Article

\title{
Health-related quality of life of patients 12 months following surgical intensive care discharge
}

\begin{abstract}
Health related quality of life (HRQoL) and the effect of selected socio-demographic and clinical intensive care variables on HRQoL of patients 12 months following adult surgical intensive care unit discharge in the Western Cape was evaluated. A prospective observational study was conducted. The sample comprised 46 patients who had survived 12 months following discharge. Structured telephonic interviews were conducted using a self-developed and SF-36v2 HRQoL questionnaire. Data was analyzed using Stastica 7 and values were accepted as significant at the 5\% level. Low mean HRQoL domain scores (43\% - 53\%) were found implying a poor HRQoL

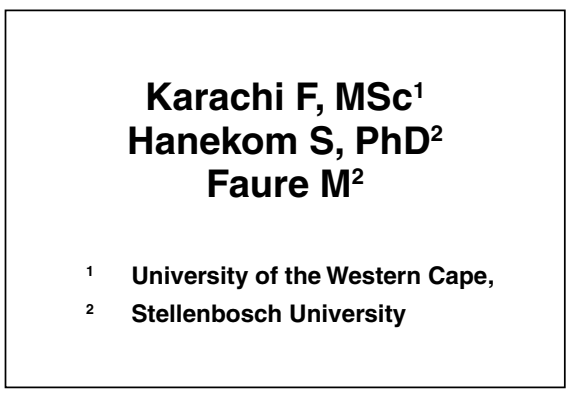
outcome. Physical functioning [43.5\%], Role Play [44.5\%] and Role Emotion [43.1\%] scores were specifically lower than the other HRQoL domain scores. Age and severity of illness scores (APACHE II) were significantly associated with the social functioning $(p=0.01)$ and physical functioning $(p=0.02)$ scores respectively. APACHE II may be a useful contributor in predicting long-term physical functioning outcomes in patients following surgical ICU discharge. The HRQoL outcomes are slightly lower than that found for international ICU populations however responses in the domains affected are comparable. Low physical functioning, role play and role emotion scores indicate a need for further physical and emotional rehabilitation following surgical ICU discharge.
\end{abstract}

\section{KEY WORDS: HEALTH RELATED QUALITY OF LIFE, SHORT FORM-36 VERSION 2, SURGICAL INTENSIVE CARE, WESTERN CAPE.}

\section{INTRODUCTION}

With advancing new medical technologies, increasing numbers of patients are surviving following intensive care management (Baker and Mansfield, 2008, van der Schaaf et al, 2009). Intensive care management generally involves prolonged periods of hospital stay (Baker and Mansfield, 2008). This decreases their physical, psychological and cognitive functioning thus leaving patients with physical and emotional disabilities and difficulties with social integration such as return

\section{Correspondence to:}

Farhana Karachi

Physiotherapy Department

University of the Western Cape

Private Bag X17

Bellville

7535

South Africa

E-mail: fkarachi@uwc.ac.za to work that impacts negatively on health related quality of life (HRQoL) following discharge (Cuthbertson et al, 2010, van der Schaaf et al, 2009). Assessment of HRQoL among intensive care survivors has therefore become an important research priority (Abelha et al, 2007). HRQoL after ICU discharge is an important issue for patients and relatives as well as health care professionals involved in the patient's treatment (Hofhuis et al, 2008b). With increasing survival rates, the long-term outcome of these survivors needs further evaluation in order to determine the effect of intensive care intervention on outcome (Abelha et al, 2007, Cuthbertson et al, 2010). The success in the prolongation of life of intensive care patients may result in a health outcome that is considered to be worse than death (Lipsett et al, 2000, Livingston et al, 2009). A patient may survive intensive care but may be severely disabled requiring continuous care as they are unable to live inde- pendently which ultimately affects their HRQoL (van der Schaaf et al, 2009). Thus, in critically ill patients establishing a good HRQoL outcome is important (Lipsett et al, 2000). The objective of rehabilitation teams should be to assist patients in reformulating their life-plan in order to lead a life with some quality. In the final outcome following intensive care the HRQoL of the patient may be affected (Cuthbertson et al, 2010). It is therefore important to assess the patients' judgment of the medical treatment and the resultant outcome (Abelha et al, 2007, Eales et al, 2000). This may give insight to the effect of medical intervention such as intensive care by enabling us to understand the long-term problems and needs of these patients. Appropriate follow-up and rehabilitation that may be required to improve a poor HRQoL outcome after intensive care discharge can then be determined (Buckley et al, 2001, van der Schaaf et al, 2009) and thereby fill the gaps in the 
care provided (Abelha et al, 2007). In South Africa ICU resources are limited and demands are great. There is also an on-going debate about which patients would benefit from this treatment. Long-term outcome such as HRQoL is therefore an important outcome to be considered in order to assess the effect and value of this care in our population (Joynt and Gomersall 2005, Michell, 2005). The latter as well as the lack of QoL outcome studies in intensive care unit (ICU) populations in South Africa (SA) and the shift of focus of outcome research in intensive care towards QoL evaluation have contributed to the need for such studies. This study is a followup to a baseline study conducted in the adult surgical intensive care unit (SICU) of a public sector tertiary hospital in the Western Cape (WC) in South Africa (SA). The purpose of the baseline study was to evaluate the profile of this SICU by describing the baseline data. The current study aimed to evaluate the HRQoL of the SICU patients who participated in the baseline study who survived 12 months following SICU discharge. The HRQoL outcome focuses on the populations' perception of their health and the effect of medical interventions on their HRQoL. It provides information on specific domains of HRQoL in which the population experiences the most problems assisting rehabilitative therapists in providing the appropriate rehabilitative management required by the specific population. As one of very few studies of this kind in SA, this study provides a baseline guide for future research in this area of intensive care especially in SA.

\section{METHODS}

Ethical approval was obtained from the Research Ethics Committee of Stellenbosch University (N04/05/092). A prospective observational study design with a population of 66 patients obtained from the baseline study who had survived 12 months following SICU discharge was then conducted. The sample was purposively chosen and consisted of 46 consenting participants. Patients younger than 18 years of age $(n=2)$, who could not respond themselves due to poor cognitive func- tion (no proxy respondents used) $(n=3)$, refused to take part $(n=5)$ and who were not contactable after four attempts but were known to have survived $(n=10)$ were excluded. Structured telephonic interviews of 15-20 minutes were carried out at the convenience of the participant after informed consent was obtained telephonically by the researcher. Consent was also obtained from each participant telephonically before obtaining answers to questions on sensitive topics such as Tuberculosis (TB) or Human Immune Deficiency Virus (HIV) status. All interviews were conducted by the same interviewer who was the main researcher and is the first author of the article. The interviewer did not influence the participants' responses in any way, and, thus, did not introduce an element of bias into the study. The participants were given three attempts to re-listen to a question if necessary and were not coerced into completing answers. All questions were answered by all participants. Socio-demographic data (age and gender) and ICU variables (admission for emergency or elective surgery or traumatic injury, severity of illness (APACHE II), length of stay (LOS), length of intubation (LOI) and treatment by student or graduate physiotherapist) were obtained from the patient database and folders through the baseline study. Other socio-demographic and clinical data such as employment status, smoking/alcohol use, TB/HIV status and follow-up status was obtained using the self-developed questionnaire. The HRQoL outcome was determined by using the Medical Outcomes Study English and/or Afrikaans Short Form36 version 2 (SF-36v2) generic health survey questionnaires as all patients spoke mainly English or Afrikaans. A license agreement (R1-061704-19248) to use the survey was obtained.

The SF-36v2 HRQoL measure has reported acceptability, validity and reliability for use within the ICU setting, has been widely used in ICU population studies and can be administered telephonically (Cuthbertson et al, 2010, Hofhuis et al, 2008a). It was the instrument of choice for this study for the above reasons. It consists of 36 items grouped into eight domains of HRQoL, namely physical functioning (PF) [10 items], role play (RP) [5 items], role emotion (RE) [3 items], bodily pain (BP) [2 items], social functioning (SF) [2 items], vitality (VT) [4 items], general health perception $(\mathrm{GH})$ [5 items] and mental health (MH) [5 items]. Each domain measures the extent to which physical and/or emotional health problems affect physical, social, emotional, psychological and psychosocial aspects of HRQoL. A self reported health transition item asks patients' how they feel their health is currently, compared to a year ago. This item is not used to score any of the eight multi-item scales mentioned above. Each domain has a set of items and options or scales. The options/ scales are measured using a Likerttype scale which is then calculated to a percentage which can range from zero [worst possible health status] to 100 [best possible health status] for each dimension. There are two summary component scores namely the physical (PCS) and mental component score (MCS). Figure 1 shows which of the eight domains contribute to each of the summary component scores. General Health and Vitality contributes to both the PCS and MCS (Abelha et al, 2007, Cuthbertson et al, 2010, Hofhuis et al, 2008a).

The SF-36v2 was scored using the electronic internet SF-36v2 scoring system and scores were checked manually using the SF-36v2 scoring manuals for accuracy by the researcher (Ware, Kosinski and Dewey, 2000a, Ware et al, 2000b, Ware and Kosinski, 2001). Statistica 7 was used to analyze and compare the data. Mean scores and standard deviations were calculated for each HRQoL domain and the two component summary scores. Mann-Whitney U, Chisquare t-tests and Spearman Correlations were used to determine associations between the different selected variables and between selected variables and the HRQoL domain scores. Results were accepted as significant at the 5\% level.

\section{RESULTS}

Forty six SICU patients participated in this study. Table 1 gives an overview of the participants' profiles regarding the selected socio-demographic and clinical 
Figure 1: SF-36 Scales Measure Physical and Mental Components of Health (Ware et al, 1994).

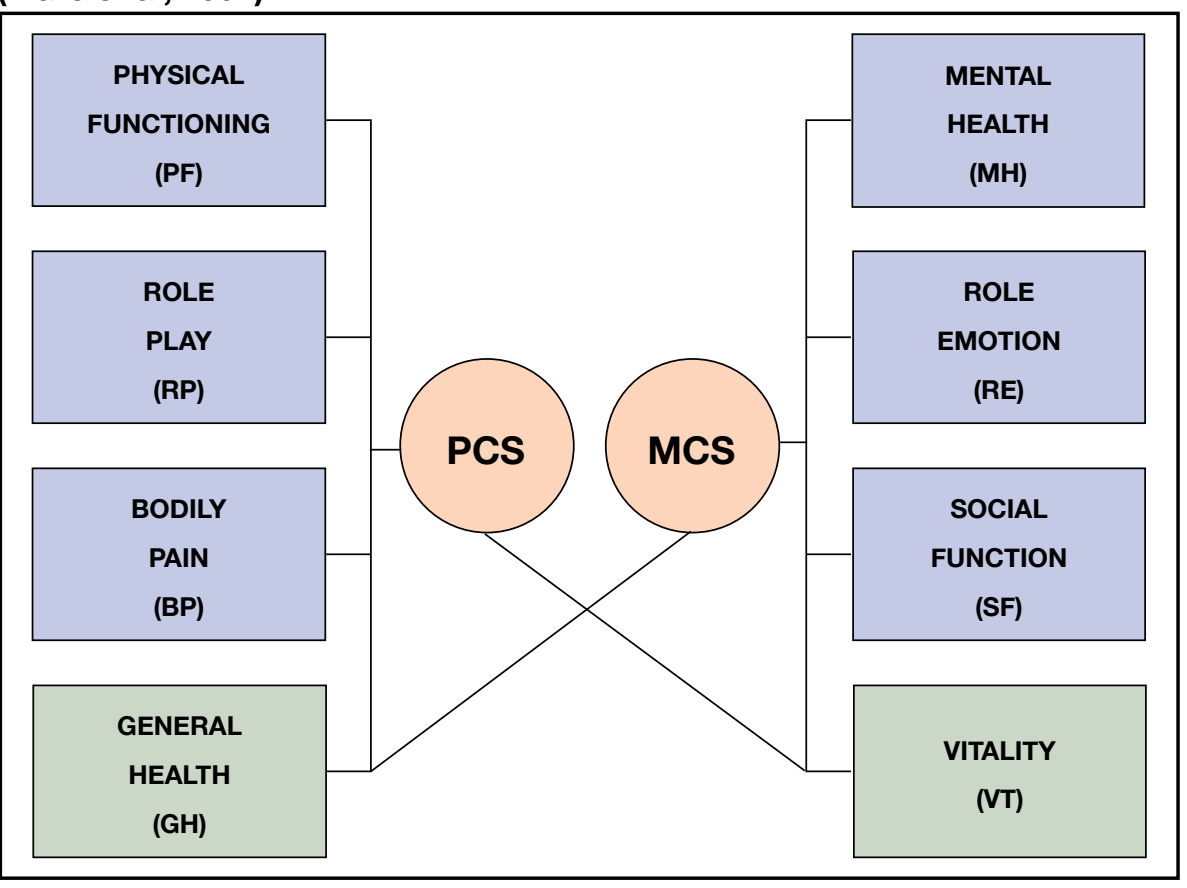

variables. Important differences noted in the table are that although females were older, they had a shorter ICU length of stay and intubation period, had a slightly lower APACHE II score, none suffered traumatic injury, fewer smoked or consumed alcohol and more attended follow-up after ICU discharge compared to the males. None of these noted differences were significant. Traumatic injury was the only variable significantly different between males and females with significantly more males sustaining traumatic injury $(\mathrm{p}=0.03)$.

Patients treated by student physiotherapists presented with significantly lower APACHE II scores $(p=0.03)$. Patients admitted to the unit following emergency surgery presented with significantly higher APACHE II scores $(\mathrm{p}=0.03)$. All patients with higher APACHE II scores had significantly longer LOS`s $(\mathrm{p}<0.01)$.

\section{HRQoL Outcomes}

Mean HRQoL outcomes for this SICU population were low ( $43 \%$ to $53 \%$ [SD $+/-9.4$-12.5]). Table 2 displays the mean percentages for each HRQoL domain. Physical functioning demonstrated the lowest score with a lower PCS than the MCS. Physical Functioning, RP and RE were the most affected HRQoL domains. In the self-reported transition question the majority of patients $(n=23)$ reported their health to be much better than a year ago following ICU discharge, five were slightly better, 10 were the same, five were slightly worse, and three were much worse than a year ago.

Table 3 represents the associations between the selected variables and the eight HRQoL domains. More severely ill patients (higher APACHE II scores) scored significantly lower in the PF domain $(\mathrm{p}=0.02)$. Social Functioning $(p<0.01)$ and $R E(p=0.03)$ significantly increased with increased age. General Health was significantly better in patients employed after SICU discharge $(p<0.01)$. Patients unsure of their TB and HIV status reported a poorer $\mathrm{GH}$ $(p=0.02)$ and $\mathrm{RE}(\mathrm{p}=0.05)$ outcome respectively. Patients requiring mechanical ventilation for a prolonged period and who would therefore have had a longer SICU LOS reported a poorer GH outcome $(p=0.04)$. An increased SICU LOS also resulted in those patients reporting significant limitations in the $R P(p=0.05)$ and $R E(p<0.01)$ domains.

\section{DISCUSSION}

A poor overall HRQoL outcome was evident (Myhren et al, 2010). The most affected HRQoL domains were PF, RP and RE. The scores of this SICU population was much lower than international populations studied indicating a definite need for more improved physical than emotional rehabilitation as was also suggested by the low PCS (Cuthbertson et al, 2010, van der Schaaf et al, 2009). The majority of SICU patients felt that their health was much better compared to a year after ICU discharge and perceived that SICU admission helped improve their health (Abelha et al, 2007). However it was clear that they were still struggling with specific areas of functioning affecting their HRQoL at 12 months therefore requiring further rehabilitation in these areas (van der Schaaf et al, 2009). Poor HRQoL due to SICU related physical and emotional restrictions necessitates the development of multidisciplinary after-care to improve outcomes (Myhren et al, 2009).

Physical functioning indicates the extent to which activities of daily living (ADL) are limited due to physical health problems. Role Play measures the extent to which physical health problems affect performance at work or other regular daily activities at home respectively such as cutting down on time spent on or accomplishing less in these activities (Möller and Smit, 2004). Slow physical recovery of ICU survivors occurs due to muscle wasting and weakness as a result of limited mobility in ICU. Poor endurance due to cardio-respiratory weakness also further restricts physical function and roles like higher functional activities such as occupational workrelated tasks or tasks within the home environment (Baker and Mansfield, 2008, van der Schaaf et al, 2009). Early intervention in SICU's, and follow up in community settings by physiotherapists and other rehabilitation therapists may help improve the SICU patients PF and RP outcome (Baker and Mansfield, 2008, van der Schaaf et al, 2009). Poor PCS's highlights the need for improved physiotherapy management and rehabilitation during and after SICU management. As the SF-36v2 PF domain measures higher levels of functioning requiring endurance it suggests that endurance exercises be incorporated into the physiotherapists rehabilitation program and advocates long-term 
Table 1. Sociodemographic and clinical variables of the participants $(n=46)$

\begin{tabular}{|c|c|c|c|}
\hline $\begin{array}{l}\text { Selected Variable } \\
\text { (Average) }\end{array}$ & $\begin{array}{l}\text { Male } \\
(n=22)\end{array}$ & $\begin{array}{l}\text { Female } \\
(n=24)\end{array}$ & $\begin{array}{l}\text { Total Population } \\
(n=46)\end{array}$ \\
\hline Age (Range: $30 y r s-81 y r s)$ & $\begin{array}{l}52.3 y r s \\
(S D+/-20)\end{array}$ & $\begin{array}{l}56.3 y r s \\
(S D+/-19.5)\end{array}$ & $\begin{array}{l}54.3 y r s \\
(S D+/-19.8)\end{array}$ \\
\hline Length of Stay (LOS) & $\begin{array}{l}6.4 d \\
(S D+/-7.8)\end{array}$ & $\begin{array}{l}3.5 d \\
(S D+/-7.5)\end{array}$ & $\begin{array}{l}4.91 d \\
(S D+/-5.52)\end{array}$ \\
\hline Length of Intubation (LOI) & $\begin{array}{l}7 \mathrm{~d}(\mathrm{n}=7) \\
(\mathrm{SD}+/-7.8)\end{array}$ & $\begin{array}{l}2.65 d(n=6) \\
(S D+/-7.5)\end{array}$ & $\begin{array}{l}3 d(n=13) \\
(S D+/-7.3)\end{array}$ \\
\hline $\begin{array}{l}\text { Admitting Diagnosis: } \\
\text { 1. Elective Surgery } \\
\text { 2. Emergency Surgery } \\
\text { 3. Traumatic Injury }\end{array}$ & $\begin{array}{l}n=6 \\
n=12 \\
n=6\end{array}$ & $\begin{array}{l}n=12 \\
n=12 \\
n=0\end{array}$ & $\begin{array}{l}n=18 \\
n=24 \\
n=6\end{array}$ \\
\hline $\begin{array}{l}\text { APACHE II Score } \\
\text { (Range: 0-38) }\end{array}$ & $\begin{array}{l}12.9 \\
(S D+/-6.21)\end{array}$ & $\begin{array}{l}11.2 \\
(\mathrm{SD}+/-6.2)\end{array}$ & $\begin{array}{l}12 \\
(\mathrm{SD}+/-6.1)\end{array}$ \\
\hline $\begin{array}{l}\text { Physiotherapy: } \\
\text { 1. Treatment by student } \\
\text { 2. Treatment by graduate }\end{array}$ & $\begin{array}{l}n=5 \\
n=17\end{array}$ & $\begin{array}{l}n=9 \\
n=15\end{array}$ & $\begin{array}{l}n=14 \\
n=32\end{array}$ \\
\hline $\begin{array}{l}\text { Employment (yes): } \\
\text { 1. before ICU } \\
\text { 2. after ICU }\end{array}$ & $\begin{array}{l}n=12 \\
n=5\end{array}$ & $\begin{array}{l}n=12 \\
n=5\end{array}$ & $\begin{array}{l}n=24 \\
n=10\end{array}$ \\
\hline $\begin{array}{l}\text { TB Status (known diagnosis): } \\
\text { 1. Yes (had TB) } \\
\text { 2. No (never had TB) } \\
\text { 3. Unsure (if they had TB) }\end{array}$ & $\begin{array}{l}n=1 \\
n=10 \\
n=11\end{array}$ & $\begin{array}{l}n=1 \\
n=11 \\
n=12\end{array}$ & $\begin{array}{l}n=2 \\
n=21 \\
n=23\end{array}$ \\
\hline $\begin{array}{l}\text { HIV Status (known diagnosis): } \\
\text { 1. Yes (HIV positive) } \\
\text { 2. No (HIV negative) } \\
\text { 3. Unsure of status }\end{array}$ & $\begin{array}{l}n=0 \\
n=10 \\
n=12\end{array}$ & $\begin{array}{l}n=0 \\
n=11 \\
n=13\end{array}$ & $\begin{array}{l}\mathrm{n}=0 \\
\mathrm{n}=21 \\
\mathrm{n}=25\end{array}$ \\
\hline $\begin{array}{l}\text { Smoking: } \\
\text { 1. Yes } \\
\text { 2. No }\end{array}$ & $\begin{array}{l}n=11 \\
n=11\end{array}$ & $\begin{array}{l}n=2 \\
n=22\end{array}$ & $\begin{array}{l}n=13 \\
n=33\end{array}$ \\
\hline $\begin{array}{l}\text { Alcohol: } \\
\text { 1. Yes } \\
\text { 2. No }\end{array}$ & $\begin{array}{l}n=11 \\
n=11\end{array}$ & $\begin{array}{l}n=5 \\
n=19\end{array}$ & $\begin{array}{l}n=16 \\
n=30\end{array}$ \\
\hline $\begin{array}{l}\text { Follow-up: } \\
\text { 1. Yes } \\
\text { 2. No }\end{array}$ & $\begin{array}{l}n=17 \\
n=5\end{array}$ & $\begin{array}{l}n=22 \\
n=2\end{array}$ & $\begin{array}{l}n=39 \\
n=7\end{array}$ \\
\hline
\end{tabular}

SD = Standard Deviation, $\mathrm{n}=$ number

rehabilitation following discharge from the acute setting.

Patients' admitted to the SICU after emergency surgery were more severely ill and had longer SICU stays experiencing decreased PF. This indicates that the severity of illness score (APACHE II) is a significant predictor of long-term PF and not only long-term survival. Longer SICU LOS resulted in more RP limitations suggesting patients were unable to endure physical work activities as they needed to cut down on the amount of work or accomplish less at work. Change or adaptation of the previous role the patient may have had, may therefore be required which can be determined and managed effectively by occupational therapists. Limitation in physical role often results in questioning the value of one's life. The outcome in this study suggests that SICU patients should prepare for a possible change in lifestyle and physical roles due to physical health problems following intensive care intervention. This however need not be the case if rehabilitation such as physiotherapy which can assist in improving muscle strength and endurance during and following intensive care management is provided as determined by HRQoL outcomes for the particular patient. Health care workers can identify possible RP limitations using HRQoL outcome measures pre and post surgical intensive care. This would assist to 
Table 2: Mean SF-36v2 HRQoL domain scores (SD) of SICU patients (n = 46)

\begin{tabular}{|l|l|l|}
\hline \multicolumn{1}{|c|}{ SF-36v2 Domains } & \multicolumn{1}{|c|}{$\begin{array}{c}\text { Mean SF-36v2 \% Scores } \\
\text { SICU (n=46) }\end{array}$} & \multicolumn{1}{c|}{ Standard Deviation (SD) } \\
\hline Physical Functioning & $43.5 \%$ & $(+/-10)$ \\
\hline Role Play & $44.5 \%$ & $(+/-10.4)$ \\
\hline Bodily Pain & $48.9 \%$ & $(+/-11.5)$ \\
\hline General Health & $46.1 \%$ & $(+/-11.9)$ \\
\hline Vitality & $52.5 \%$ & $(+/-9.5)$ \\
\hline Social Functioning & $47.6 \%$ & $(+/-10.9)$ \\
\hline Role Emotion & $43.1 \%$ & $(+/-12.5)$ \\
\hline Mental Health & $50.7 \%$ & $(+/-8.7)$ \\
\hline Physical Component Score & $45.8 \%$ & $(+/-10)$ \\
\hline Mental Component Score & $49.1 \%$ & $(+/-10.4)$ \\
\hline
\end{tabular}

Table 3: Association between selected variables with SF-36v2 HRQoL domains (*significant p-values)

\begin{tabular}{|l|l|l|l|l|l|l|l|l|}
\hline \multicolumn{1}{|c|}{ Selected Variable } & PF & BP & VT & SF & MH & RP & RE & GH \\
\hline Age & 0.06 & 0.44 & 0.97 & $<0.01^{*}$ & 0.07 & 0.58 & $\mathbf{0 . 0 3 ^ { * }}$ & 0.28 \\
\hline Gender & 0.41 & 0.13 & 0.11 & 0.22 & 0.57 & 0.79 & 0.58 & 0.49 \\
\hline APACHE II & $\mathbf{0 . 0 2 ^ { * }}$ & 0.83 & 0.28 & 0.73 & 0.54 & 0.58 & 0.7 & 0.09 \\
\hline Employed after ICU & 0.12 & 0.74 & 0.43 & 0.99 & 0.65 & 0.39 & 0.96 & $<0^{*}$ \\
\hline Unsure TB status & 0.17 & 0.10 & 0.36 & 0.72 & 0.80 & 0.06 & 0.07 & $\mathbf{0 . 0 2}^{*}$ \\
\hline Unsure HIV status & 0.15 & 0.15 & 0.54 & 0.33 & 0.98 & 0.1 & $\mathbf{0 . 0 5 ^ { * }}$ & 0.06 \\
\hline Alcohol & 0.96 & 0.23 & 0.54 & 0.12 & 0.18 & 0.3 & 0.08 & 0.11 \\
\hline Smoking & 0.6 & 0.48 & 0.62 & 0.83 & 0.71 & 0.97 & 0.98 & 0.67 \\
\hline Treatment by student & 0.63 & 0.38 & 0.81 & 0.61 & 0.45 & 0.76 & 0.64 & 0.23 \\
\hline Physiotherapist & & & & & & & & \\
\hline Elective & 0.26 & 0.97 & 0.33 & 0.41 & 0.21 & 0.51 & 0.33 & 0.74 \\
\hline Traumatic & 0.15 & 0.80 & 0.37 & 0.61 & 0.57 & 0.52 & 0.33 & 1.0 \\
\hline ICU LOS & 0.67 & 0.90 & 0.97 & 0.30 & 0.45 & 0.09 & 0.43 & 0.88 \\
\hline Intubation period & 0.06 & 0.9 & 0.69 & 0.89 & 0.86 & $\mathbf{0 . 0 5}$ & $<0.01^{*}$ & 0.16 \\
\hline Follow-up & 0.34 & 0.95 & 0.07 & 0.43 & 0.98 & 0.25 & 0.55 & $\mathbf{0 . 0 4}$ \\
\hline
\end{tabular}

Key: Physical Functioning (PF), Bodily Pain (BP), Vitality (VT), Social Functioning (SF), Mental Health (MH), Role Play (RP), Role Emotion (RE), General Health (GH)

provide the necessary guidance in disengaging in one's (the patient) previous role central to their identity. It will aid in developing a new identity in a new role that takes into account the patients' previous role and thereby improve HRQoL.
Role Emotion measures the extent to which emotional health problems affect performance at work or other regular daily activities at home respectively namely cutting down on time spent on or accomplishing less in these activities
(Möller and Smit, 2004). The effect of emotional trauma due to high levels of psychological distress including posttraumatic disorder in ICU patients (van der Schaaf et al, 2009) supports the poor RE outcome. SICU patients unsure of 
their HIV status scored significantly lower in this domain than those with a known negative HIV status. Not knowing one's HIV status even after being tested may lead to undue stress with negative emotional effects and poorer RE outcomes. Patients with longer SICU LOS's experienced more problems with RE. The effect of SICU stay may result in delirium, hallucination and problems with short term memory due to the stress of illness, drugs, sleep deprivation, to name a few, which may result in emotional health problems that later affect functional roles (van der Schaaf et al, 2009). Elderly SICU patients reported less limitation in RE than younger survivors. This may suggest that elderly survivors have adapted to their long-term illnesses and accepted their decrease in functional roles having more positive health attitudes compared to younger patients who are accustomed to being active, seek employment and need to work for an income and therefore have different expectations (Abelha et al, 2007, Eddleston et al, 2000). Elderly patients did not experience the same limitations as younger patients because they lived with family, did not have to work and belonged to social groups. On the other hand younger patients may stay alone and have to continue with work and support their families. Referral and long-term management by psychologists, social workers, etc in order to improve psychological support and social integration following SICU discharge may improve RE outcomes (van der Schaaf et al, 2009).

These patients perceived their emotional and physical health to negatively affect their social interaction (SF) with family, friends and social groups or clubs. They perceived themselves to be more nervous and depressed than calm, peaceful and happy (MH), have less energy and life, being more tired and worn out (VT) and that they were generally sicker than other people they knew. They believed their health would become worse and that they have a poor health status (GH). It is crucial to people suffering from ill-health to have social support as humans are social by nature (Möller and Smit, 2004). This population had greater SF limitations than international populations (Cuthbertson et al, 2010, Hofhuis et al, 2008b). The elderly patients had a better perception of their SF than the younger patients as they either stayed with their families or in care facilities where they were taken care of. They had more time to have social interactions by attending social groups or clubs or spend time with their family and friends. It is important for health care workers to pay attention to SF of SICU patients in order to establish a sense of cohesion and the experience of security (Möller and Smit, 2004). Lower $\mathrm{MH}$ scores corresponded to more negative feelings and were lower than international scores (Cuthbertson et al, 2010). It is important to achieve normal mental health or well-being in SICU patients in order to improve SF and social role performance. Health care workers trained in this area need to be incorporated into the medical management team in SICU's to assist patients with mental recovery. Low vitality scores meant that patients did not feel full of life or energetic but felt tired or worn out (Möller and Smit, 2004). General health perception measures how good or bad patients perceive their health to be, perceived comparison of health to other people they know and the expectation of their health worsening (Möller and Smit, 2004). Prolonged mechanically ventilated patients and patients unsure of their TB status showed poorer $\mathrm{GH}$ scores. TB affects the respiratory system therefore critically ill patients with TB may need prolonged ventilation which in itself further affects respiratory functioning explaining the poor GH perception. GH was better in patients employed 12 months after SICU. Only 22\% of this sample was employed compared to $50 \%$ reported by Myhren et al (2010) who also reported better HRQoL.

Bodily pain refers to how much pain the patient experiences and how often the amount of pain interferes with their work-related tasks at work and at home or regular daily activities. The low BP score indicated that this population experienced more than very mild pain such as moderate to severe pain which resulted in limitations in work and ADL (Möller and Smit, 2004). This could be that SICU patients experience more painful procedures in ICU such as specific surgical procedures, the insertion of intravenous and arterial lines, nasogastric tubes, catheters and suctioning than other patients. This pain experienced may linger for months after discharge therefore affecting physical functioning. This is particularly evident for this group of SICU patients compared to other patients as pain is a common and expected occurrence following surgical procedures. Persistent pain causes a stress response in the body which suppresses the immune system and results in post surgical infection and poor wound healing. This ultimately limits function and has an adverse effect on physical and psychological outcomes as chronic pain causes decreased physical activity, anxiety and depression affecting HRQoL (Wells et al, 2008). Bodily Pain scores were lower than international scores (Cuthbertson et al, 2010, Myhren et al, 2010). More attention to the treatment of patients with severe pain following surgical intensive care is required. Health care facilities should develop strategies to cater for the after care of SICU patients. Physiotherapists could play a role in this area by incorporating pain reducing modalities into their treatment regime as applicable in ICU and following discharge.

Comparison of HRQoL scores to the general SA population was impossible as no normative data is available for the HRQoL outcome measure used. However, this SICU population had clinically and socially relevant lower HRQoL scores than international SICU populations. This substantiates the definite need for improvement in HRQoL in SICU patients in the WC and SA. The small sample size does not allow generalization of outcomes to the entire WC SICU population however the outcomes may serve as an exemplar for the appropriate management of patients with these characteristics to improve the HRQoL outcomes. Further studies including bigger samples and longer follow-up both pre and post surgical intensive care are recommended. This will help determine whether SA SICU populations with prolonged surgical illness are recovering and improving over time and if not which areas require 
improvement. Health care workers can then provide the most appropriate medical, physical, social and psychological support or rehabilitation to improve HRQoL outcomes. This study contributes to the literature as it provides insight into the perception of SA SICU patients regarding their health and the effect of SICU interventions on their HRQoL and the specific domains affected. This can assist rehabilitative therapists to improve SICU patients HRQoL that may lead to a positive effect on their rehabilitation and social integration. In conclusion HRQoL outcome measures should be used pre and post operatively to evaluate medical intervention such as acute intensive care management in order to have a client-centered approach to rehabilitation post SICU to improve and increase the HRQoL of these survivors.

\section{REFERENCES}

Abelha FJ, Santos CC, Maia PC, Castro1 MA, Barros H 2007 Quality of life after stay in surgical intensive care unit. Biomed Central Anesthesiology, 7:8

Baker C, Mansfield L 2008 Physical rehabilitation following critical illness. Journal of Intensive Care S, 9(2): 166-169.
Buckley TA, Cheng AYC, Gomersall CD 2001 Quality of life in long-term survivors of intensive care. Annals Academy of Medicine Singapore, 30(3): 287-292.

Cuthbertson BH, Roughton S, Jenkinson D, MacLennan G, Vale L 2010 Quality of life in the five years after intensive care: a cohort study. Critical Care 14(1): R6.

Eales CJ, Stewart AV, Noakes TD 2000 Chronic Illness and Quality of Life. South African Journal of Physiotherapy, 56(4): 10-16.

Eddleston JM, White P, Guthrie E 2000 Survival, morbidity, and quality of life after discharge from intensive care. Critical Care Medicine, 28(7): 2293-2299.

Joynt GM, Gomersall CD 2005 Making moral decisions when resources are limited - an approach to triage in ICU patients with respiratory failure. South African Journal of Critical Care, 21(1): 34-44.

Lipsett PA, Swoboda SM, Dickerson J, Ylitalo M, Gordon T, Breslow M, Campbel K, Dorman T, Pronovost P, Rosenfeld B 2000 Survival and Functional Outcome after Prolonged Intensive Care Unit Stay. Annals of Surgery, 231(2): 262-268.

Livingston DH, Tripp T, Biggs C, Lavery RF A fate worse than death? Long-term outcome of trauma patients admitted to the surgical intensive care unit.

Michell WL 2005 Editorial: Who is too sick for the ICU? South African Journal of Critical Care, 21(1): 8 .
Möller PH, Smit R 2004 Measuring health-related quality of life: A comparison between people living with Aids and police on active duty. Health SA Gesondheid, 9(2): 31-42.

Myhren H, Ekeberg Ø, Stokland O 2010 Healthrelated quality of life and return to work after critical illness in general intensive care unit patients: A 1-year follow-up study. Critical Care Medicine, 38(7): 1554-1561.

van der Schaaf M, Beelen A, Dongelmans DA, Vroom MB, Nollet F 2009 Poor functional recovery after a critical illness: A longitudinal study. Journal of Rehabilitation Medicine, 41: 1041-1048.

Ware JE, Kosinski M 2001 SF-36 ® Physical and Mental Health Summary Scales: A Manual for users of version 1, 2nd edn, Lincoln, RI: QualityMetric Incorporated.

Ware JE, Kosinski M, Dewey JE 2000a How to score Version 2 of the SF-36 ${ }^{\circledR}$ Health Survey. Lincoln, RI: QualityMetric Incorporated.

Ware JE, Kosinski M, Gandek B 2000b SF-36 ® Health Survey: Manual \& Interpretation Guide. Lincoln, RI: QualityMetric Incorporated.

Ware JE, Kosinski M, Keller SK 1994 SF-36® Physical and Mental Health Summary Scales: A User's Manual. Boston, MA: The Health Institute.

Wells N, Pasero C, McCaffery M 2008 Improving the Quality of Care Through Pain Assessment and Management. In: Hughes RG (ed) Patient Safety and Quality: An Evidence-Based Handbook for Nurses, Vol. 1, Ch.17, pp 1. AHRQ Publication No. 08-0043, Rockville, MD: Agency for Healthcare Research and Quality. 